\title{
Self-Sensing 3D Printed Repair for Concrete Substrates
}

\author{
CHRISTOS VLACHAKIS, LORENA BIONDI, JACK MCALORUM \\ and MARCUS PERRY
}

\begin{abstract}
Continuous monitoring allows informed maintenance to more effectively prolong the lifespan of civil infrastructure. In this paper, we outline a 3D printing process for smart materials that could simultaneously support the distributed sensing and maintenance of reinforced concrete structures. The smart material employed in this research is alkali-activated metakaolin. It is already well-known that alkali activated metakaolin can attain comparable mechanical characteristics to ordinary Portland cement and is thus able to repair and restore the structural integrity of damaged concrete infrastructure. However, these materials also exhibit a higher electrical conductivity than conventional cements due to the presence of free ions in their matrix. This allows temperature and strain to be monitored through variations in electrical impedance. Here, we demonstrate additive manufacturing of these materials to allow remote installation, with greater design flexibility and repeatability. In this paper, the electrical response of printed samples is outlined, and we discuss how sensor data can be interpreted to detect strain variations for structural health monitoring applications.
\end{abstract}

\section{INTRODUCTION}

Concrete has been widely used throughout the construction sector. In order to ensure the proper and safe performance of concrete structures, monitoring and maintenance is required. As a result, sensors have been incorporated for strain and temperature detection. Alternative means of effectively monitoring infrastructure include self-sensing materials. Such materials are able to detect variations in strain and in temperature without the use of additional devices.

Christos Vlachakis, Lorena Biondi, Jack McAlorum, Marcus Perry

Civil and Environmental Engineering, University of Strathclyde, 75 Montrose St, Glasgow, G1 1XJ Scotland, UK 
Over the past decades alkali activated materials, also referred to as geopolymers [1], have gained increasing interest. These materials are alternative binders to ordinary Portland cement (OPC) [2] due to their comparable mechanical properties to OPC binders [3] and to their potential to reduce greenhouse gas emissions [4]. Alkali activated materials require a solid aluminosilicate precursor, typically metakaolin, fly ash or blast furnace slag [5], in addition to a liquid alkaline activator (usually sodium silicate and a hydroxide, $\mathrm{MOH}$, where $\mathrm{M}=\mathrm{K}$ or Na) to initiate the hardening process [6]. The action that transpires when these are all mixed together is referred to as alkaline activation or geopolymerization. This includes a series of reactions such as: dissolution, rearrangement, condensation and resolidification [7]. Due to the alkaline solution in their pores, these materials are more electrically conductive than OPC [8] and thus have seen numerous self-sensing applications [8-13].

Recently, concrete has seen a new means of casting and fabrication. Instead of conventional moulding, cementitious materials can be extruded through a nozzle in a layer-by-layer process, otherwise known as additive manufacturing or 3D printing. This method allows for more complex designs without the use of formwork. Printable mixes differ from common cement mixes [14]. For this reason the mix used must demonstrate an adequate extrudability, buildability, workability and open time [15]. Alkali activated materials have also been employed in 3D printing applications. Alkali activated slag and fly ash objects were printed using the powder bed method in [16]. Panda et al. [17] 3D printed fiber reinforced activated fly ash. Franchin et al. [18] printed metakaolin and fly ash lattices using the syringe-based direct ink writing method. Finally Zhong et al. [19] used graphene geopolymer to print conductive specimens.

In this paper an alkali activated 3D printed self-sensing repair is presented and its electrical response under compression is investigated.

\section{METHODOLOGY}

In this section the materials used and the procedure for formulating, extruding, and electronically testing the patch samples are outlined.

\section{Materials}

Metakaolin was produced by calcining highly refined china clay originating from the United Kingdom, in an electric furnace at $800{ }^{\circ} \mathrm{C}$ for 2 hours. Commercially supplied undensified silica fume was also added due to its simultaneous beneficial effects on bond strength [20] and buildability [21]. The properties of these two materials are presented in Table I. Polyvinyl alcohol PVA fibers $(3 \mathrm{~mm})$ were also added to improve adhesion and crack resistance [22]. The alkaline activator was prepared by mixing commercial sodium silicate $\left(\mathrm{Na}_{2} \mathrm{O}=8.5 \%, \mathrm{SiO}_{2}=27.8 \%, \mathrm{H}_{2} \mathrm{O}=63.7 \%\right)$ and sodium hydroxide $10 \mathrm{M}$. The mass ratio of solution used for this experiment was $\mathrm{Na}_{2} \mathrm{SiO}_{3}$ : $\mathrm{NaOH}=2.5$. The solution was left to cool for at least $24 \mathrm{~h}$ prior to use. 
TABLE I MATERIAL PROPERTIES

\begin{tabular}{|l|l|l|l|}
\hline & $\mathrm{SiO}_{2}$ & $\mathrm{Al}_{2} \mathrm{O}_{3}$ & Mean particle size \\
\hline Kaolin & $47 \%$ mass & $38 \%$ mass & $10 \mu \mathrm{m}$ \\
\hline Silica fume & $92 \%$ & - & $<1 \mu \mathrm{m}$ \\
\hline
\end{tabular}

The solid to liquid ratio of the paste was 0.85 . The precursor consisted of $95 \%$ metakaolin and $5 \%$ silica fume. $0.5 \%$ of total weight PVA $(3 \mathrm{~mm})$ fibers were added. Metakaolin, silica fume and PVA fibers were dry mixed for $5 \mathrm{~min}$ to ensure homogeneity. The activator was then poured into the dry materials and mixed for at least 10 minutes until a homogeneous mix was obtained.

\section{D printing}

For extrusion, a progressive cavity dosing pen was installed onto the $x-y$ stage of a $3 \mathrm{D}$ printer. The material for extrusion was inserted into the cartridge as depicted in Figure 1.

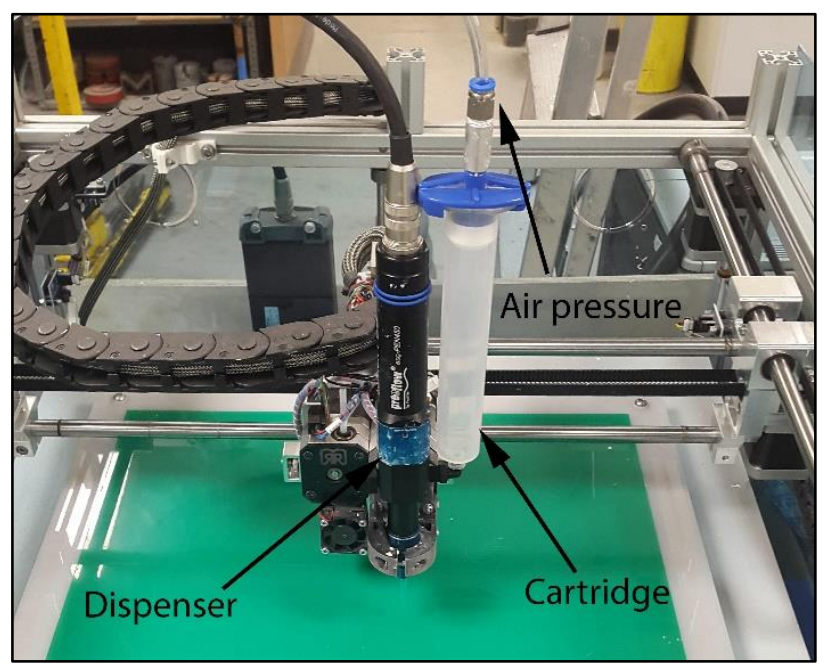

Figure 1.3D printing setup

A square patch with dimensions $40 \mathrm{~mm} \times 40 \mathrm{~mm} \times 1.6 \mathrm{~mm}$ was printed onto a $100 \mathrm{~mm} \times 100 \mathrm{~mm} \times 100 \mathrm{~mm}$ concrete cube using a print speed of $50 \mathrm{~mm} / \mathrm{s}$. The nozzle size was $0.84 \mathrm{~mm}$ and the layer height $0.66 \mathrm{~mm}$. The concrete surface was wire brushed to ensure greater adhesion with the deposited geopolymer [23]. After extrusion, the specimen was sealed in a plastic container and cured at $40{ }^{\circ} \mathrm{C}$ for $24 \mathrm{~h}$. It was then stored under ambient conditions until testing. Figure 2 shows an image of a printed patch. 


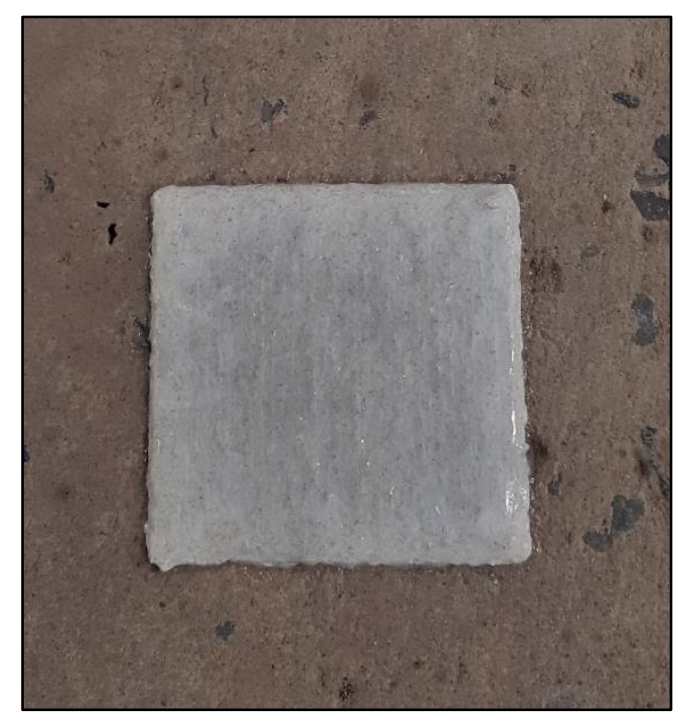

Figure 2. Metakaolin based printed patch

\section{Electrical testing}

The electronic impedance of the sample was tested with an electrical impedance analyser using a four-probe set up. The specimen was placed onto a universal loading cell with a maximum load capacity of $50 \mathrm{kN}$. The cube was loaded incrementally up to $5 \mathrm{kN}$ and then unloaded with a step of $1 \mathrm{kN}$ while applying $\mathrm{V}=10 \mathrm{mV}$ to the printed patch at an ac frequency of $5 \mathrm{kHz}$. The current, $\mathrm{I}$, was measured, allowing electrical impedance to be extracted as V $=\mathrm{IZ}$.

\section{RESULTS}

Figure 3 depicts the change of the modulus of electrical impedance, $Z_{\bmod }$, against time and load application. It can be seen that the impedance values increased upon loading and decreased when the loads were removed. The initial and final impedance values are equal, indicating a reversible sensing capability, albeit with a higher sensitivity at low load.

The change in impedance is due to the piezoresistive effect which allows for a material's electrical response to change under an applied stress. Similar to OPC, alkali activated materials also exhibit this effect $[8,13]$. As mentioned, the change in impedance in self-sensing alkali activated materials is a result of changes to ion migration $[10,12]$. In this instance, we observe an increase in impedance rather than a decrease (a decrease would be considered the norm under compression [24]). It could be that micro-cracks are being developed under load, interfering with ion migration thus causing an increase in impedance [12] rather than a decrease, but this result does require further investigation. 


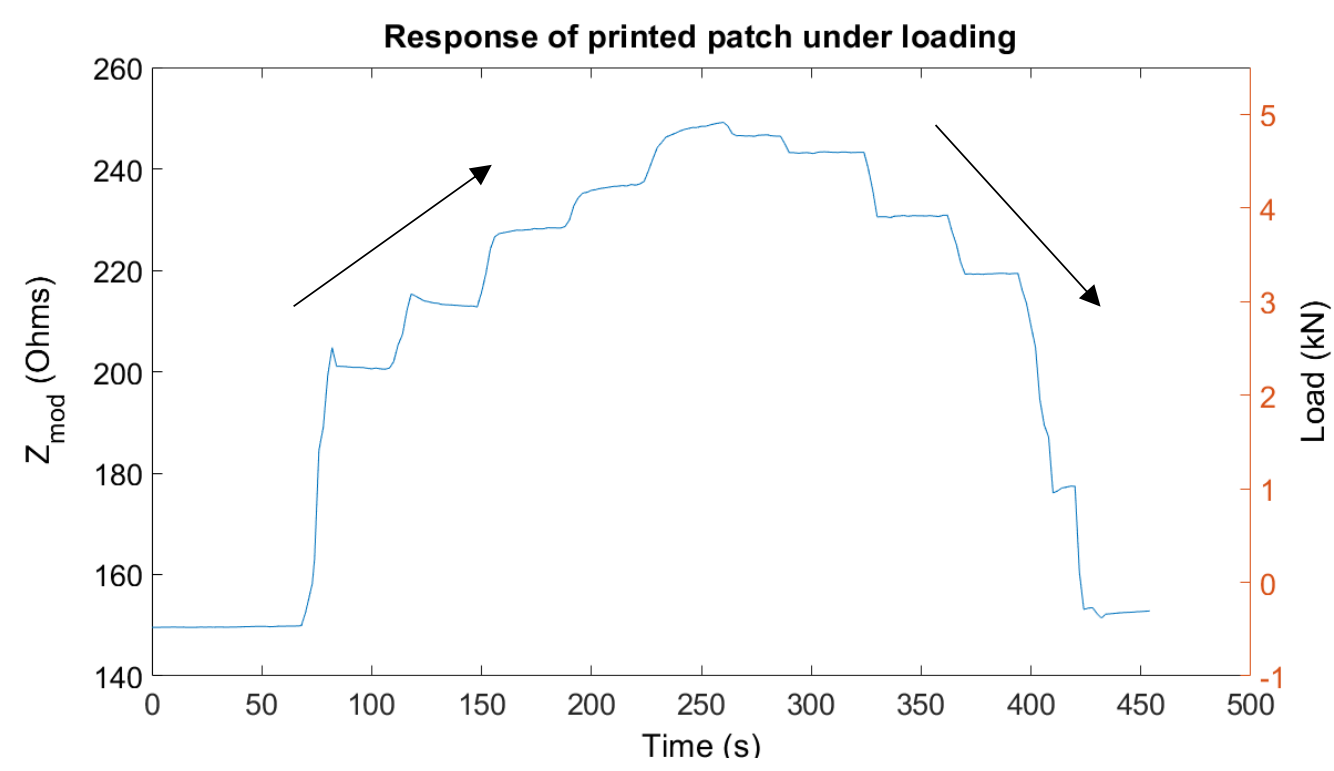

Figure 3. Response of printed patch under compression

Strain sensors are usually evaluated by their gauge factor (GF). The gauge factor indicates the fractional change of electrical properties in regards to the respective strain. The gauge factor is calculated with equation (1):

$$
\mathrm{k}=\left(\Delta \mathrm{Z} / \mathrm{Z}_{0}\right) \boldsymbol{\varepsilon},
$$

where $\mathrm{k}=$ gauge factor, $\mathrm{Z}_{0}=$ initial impedance, $\Delta \mathrm{Z}=$ the change in impedance $\mathrm{Z}_{\mathrm{i}}$ $\mathrm{Z}_{0}$ and $\varepsilon=$ strain. Strain can be determined through equation (2):

$$
\varepsilon=\sigma / \mathrm{E},
$$

where $\sigma=$ strain and $\mathrm{E}=30 \mathrm{GPa}$ (modulus of elasticity). Figure 4 depicts the fractional increase in impedance for loading and figure 5 for unloading.

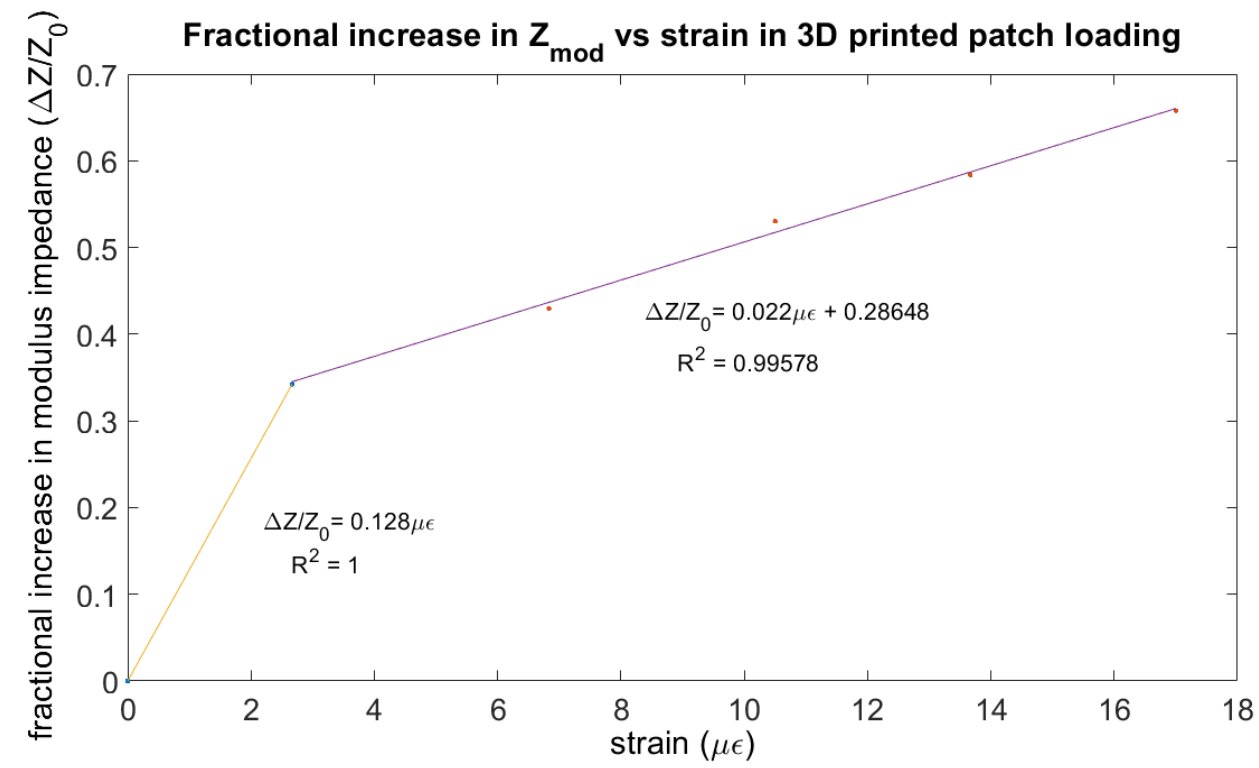

Figure 4. Fractional increase in impedance for loading 


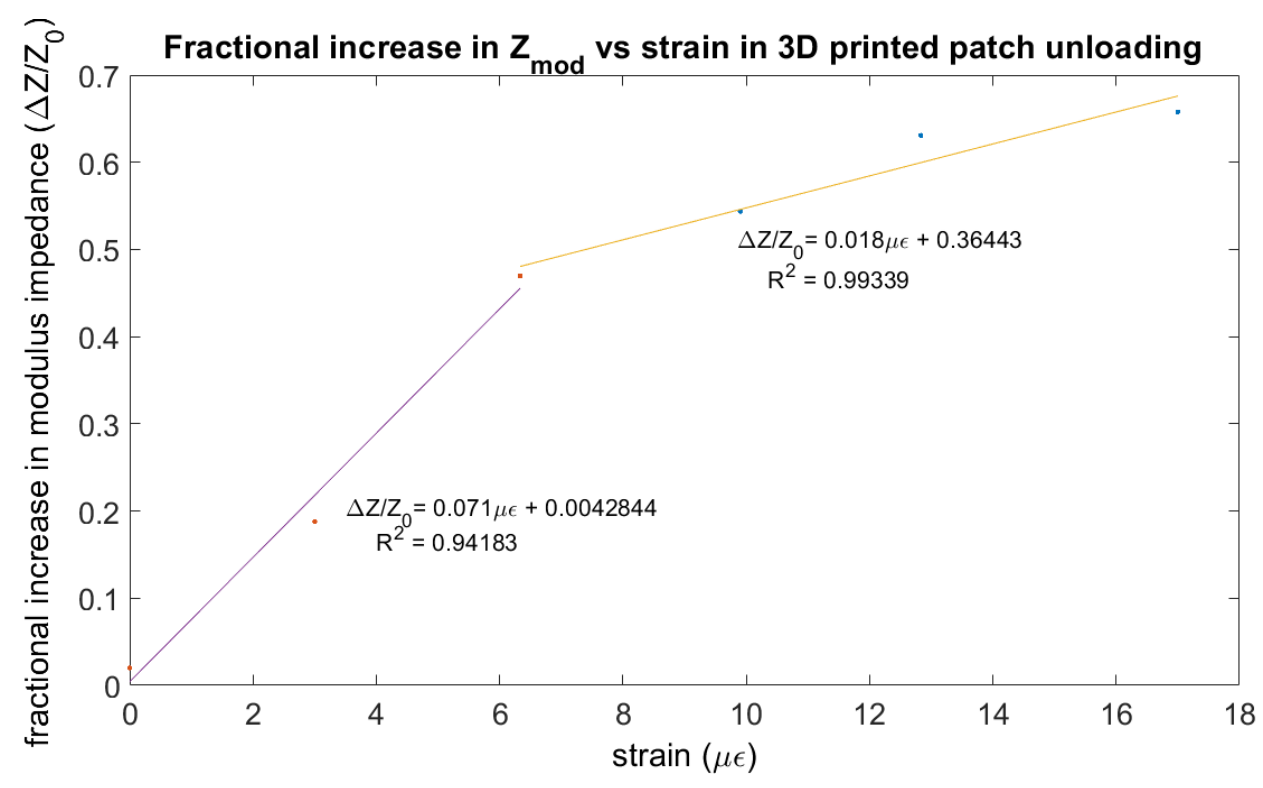

Figure 5. Fractional increase in impedance for reverse loading

The sensor's behaviour is fairly linear for strains above $4 \mu \varepsilon$ for loading and $6 \mu \varepsilon$ under unloading conditions. As it could be seen in figures 4 and 5 the gauge factor for lower strains $(0.128 \mu \varepsilon, 0.071 \mu \varepsilon)$ is greater than the gauge factor for higher strains $(0.022 \mu \varepsilon \quad 0.018 \mu \varepsilon)$ respectively. This signals a higher sensitivity for lower loads causing a somewhat nonlinear response upon load increase. Moreover the patch's sensing capability was slightly reduced upon unloading $(0.071 \mu \varepsilon$ compared to $0.128 \mu \varepsilon$ and $0.018 \mu \varepsilon$ compared to $0.022 \mu \varepsilon)$. Both these events could be explained due to the formation of cracks that have developed during initial loading, thus having a negative impact on the extruded patch's monitoring performance, but this does require further investigation.

\section{CONCLUSIONS}

In this work the electrical response of an extruded patch onto a concrete cube was presented. The sensing repair presented a reversible sensing capability. Its impedance increased under loading and decreased when the loads were removed. The increase in impedance is speculated to occur due to cracks in the sample therefore hindering ion migration. The change in sensing capability between cycles can also be attributed due to crack formation.

\section{REFERENCES}

[1] Davidovits J. Geopolymers: inorganic polymeric new materials. J Therm Anal 1991;37:1633-56. doi:10.1007/BF01912193.

[2] Van Deventer JSJ, Provis JL, Duxson P. Technical and commercial progress in the adoption of geopolymer cement. Miner Eng 2012;29:89-104. doi:10.1016/j.mineng.2011.09.009.

[3] Provis JL, Bernal SA. Geopolymers and Related Alkali-Activated Materials. Annu Rev 
Mater Res 2014;44:299-327. doi:10.1146/annurev-matsci-070813-113515.

[4] McLellan BC, Williams RP, Lay J, Van Riessen A, Corder GD. Costs and carbon emissions for geopolymer pastes in comparison to ordinary portland cement. J Clean Prod 2011;19:1080-90. doi:10.1016/j.jclepro.2011.02.010.

[5] Duxson P, Provis JL. Designing precursors for geopolymer cements. J Am Ceram Soc 2008;91:3864-9. doi:10.1111/j.1551-2916.2008.02787.x.

[6] Provis J. Activating solution chemistry for geopolymers. In: Geopolymers: Structure, processing, properties and industrial applications. Cambridge: Woodhead; 2009.

[7] Provis JL. Geopolymers and other alkali activated materials: Why, how, and what? Mater Struct Constr 2014;47:11-25. doi:10.1617/s11527-013-0211-5.

[8] Saafi M, Tang L, Fung J, Rahman M, Sillars F, Liggat J, et al. Graphene/fly ash geopolymeric composites as self-sensing structural materials. Smart Mater Struct 2014;23. doi:10.1088/0964-1726/23/6/065006.

[9] Saafi M, Piukovics G, Ye J. Hybrid graphene/geopolymeric cement as a superionic conductor for structural health monitoring applications. Smart Mater Struct 2016;25. doi:10.1088/0964-1726/25/10/105018.

[10] Saafi M, Gullane A, Huang B, Sadeghi H, Ye J, Sadeghi F. Inherently multifunctional geopolymeric cementitious composite as electrical energy storage and self-sensing structural material. Compos Struct 2018;201:766-78. doi:10.1016/j.compstruct.2018.06.101.

[11] Perry M, Saafi M, Fusiek G, Niewczas P. Hybrid optical-fibre/geopolymer sensors for structural health monitoring of concrete structures. Smart Mater Struct 2015;24. doi:10.1088/0964-1726/24/4/045011.

[12] Bi S, Liu M, Shen J, Hu XM, Zhang L. Ultrahigh Self-Sensing Performance of Geopolymer Nanocomposites via Unique Interface Engineering. ACS Appl Mater Interfaces 2017;9:12851-8. doi:10.1021/acsami.7b00419.

[13] Lamuta C, Bruno L, Candamano S, Pagnotta L. Piezoresistive characterization of graphene/metakaolin based geopolymeric mortar composites. MRS Adv 2017;2:3773-9. doi:10.1557/adv.2017.595.

[14] Paul SC, Tay YWD, Panda B, Tan MJ. Fresh and hardened properties of 3D printable cementitious materials for building and construction. Arch Civ Mech Eng 2018;18:3119. doi:10.1016/j.acme.2017.02.008.

[15] Le TT, Austin SA, Lim S, Buswell RA, Gibb AGF, Thorpe T. Mix design and fresh properties for high-performance printing concrete. Mater Struct Constr 2012;45:122132. doi:10.1617/s11527-012-9828-z.

[16] Xia M, Sanjayan J. Method of formulating geopolymer for 3D printing for construction applications. Mater Des 2016;110:382-90. doi:10.1016/j.matdes.2016.07.136.

[17] Panda B, Chandra Paul S, Jen Tan M. Anisotropic mechanical performance of 3D printed fiber reinforced sustainable construction material. Mater Lett 2017;209:146-9. doi:10.1016/j.matlet.2017.07.123.

[18] Franchin G, Scanferla P, Zeffiro L, Elsayed H, Baliello A, Giacomello G, et al. Direct ink writing of geopolymeric inks. J Eur Ceram Soc 2017;37:2481-9. doi:10.1016/j.jeurceramsoc.2017.01.030.

[19] Zhong J, Zhou GX, He PG, Yang ZH, Jia DC. 3D printing strong and conductive geopolymer nanocomposite structures modified by graphene oxide. Carbon N Y 2017;117:421-6. doi:10.1016/j.carbon.2017.02.102.

[20] Momayez A, Ehsani MR, Ramezanianpour AA, Rajaie H. Comparison of methods for evaluating bond strength between concrete substrate and repair materials. Cem Concr Res 2005;35:748-57. doi:10.1016/j.cemconres.2004.05.027.

[21] Kazemian A, Yuan X, Cochran E, Khoshnevis B. Cementitious materials for construction-scale 3D printing: Laboratory testing of fresh printing mixture. Constr Build Mater 2017;145:639-47. doi:10.1016/j.conbuildmat.2017.04.015.

[22] Zanotti C, Borges PHR, Bhutta A, Banthia N. Bond strength between concrete substrate and metakaolin geopolymer repair mortar: Effect of curing regime and PVA fiber reinforcement. Cem Concr Compos 2017;80:307-16. doi:10.1016/j.cemconcomp.2016.12.014.

[23] Júlio ENBS, Branco FAB, Silva VD. Concrete-to-concrete bond strength. Influence of the roughness of the substrate surface. Constr Build Mater 2004;18:675-81. doi:10.1016/j.conbuildmat.2004.04.023.

[24] Han B, Ding S, Yu X. Intrinsic self-sensing concrete and structures: A review. Meas J Int Meas Confed 2015;59:110-28. doi:10.1016/j.measurement.2014.09.048. 